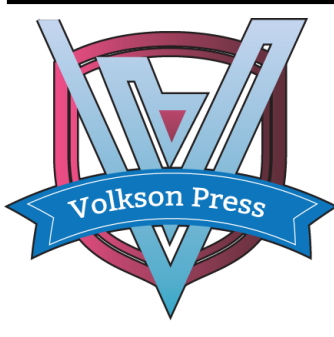

Contents List available at VOLKSON PRESS

New Materials and Intelligent Manufacturing (NMIM) DOI : http://doi.org/10.26480/icnmim.01.2018.79.82

Journal Homepage: https://topicsonchemeng.org.my/

ISBN: 978-1-948012-12-6

\title{
EFFECT OF SINTERING TEMPERATURE AND TIME ON STRUCTURAL AND DIELECTRIC PROPERTIES OF TB-DOPED BATIO ${ }_{3}$ CERAMICS
}

\author{
Dayong $\mathrm{Lu}^{1^{*}}$, Xianglu Gao', Yuchun $\mathrm{Fu}^{2}$
}

${ }^{1}$ Key Laboratory for Special Functional Materials in Jilin Provincial Universities, Jilin Institute of Chemical Technology Chengde Street 45, Jilin 132022, China

${ }^{2}$ Department of Materials Chemistry, Jilin Institute of Chemical Technology Chengde Street 45, Jilin 132022, China

*Corresponding Author Email: dylu@jlict.edu.cn

This is an open access article distributed under the Creative Commons Attribution License, which permits unrestricted use, distribution, and reproduction in any medium, provided the original work is properly cited

\section{ARTICLE DETAILS}

Article History:

Received 26 June 2018

Accepted 2 July 2018

Available online 1 August 2018

\section{ABSTRACT}

$\mathrm{Ba}_{1-x / 2} \mathrm{Ti}_{1-x / 2} \mathrm{~Tb}_{x} \mathrm{O}_{3}(x=0.05)$ ceramics (BTTb5) were prepared at $T_{\mathrm{s}}=1400{ }^{\circ} \mathrm{C}$ for $t=6-24 \mathrm{~h}$ and at $T_{\mathrm{s}}=1300-1480{ }^{\circ} \mathrm{C}$ for $t=24 \mathrm{~h}$ using the cold-pressing ceramic processing technique. All of BTTb5 ceramics satisfy EIA X5R dielectric specification and exhibit a tetragonal perovskite structure. The sintering temperature and the sintering time have little influence on the crystal structure and dielectric properties of BTTb5. The optimum preparation condition of BTTb5 is determined as $T_{\mathrm{s}}=1400^{\circ} \mathrm{C}$ for $t=12 \mathrm{~h}$ because of higher relative density $\left(\rho_{\mathrm{r}}=94 \%\right)$ and lower dielectric loss $(\tan \delta=0.0108)$. As the sintering time increases, the XRD and EPR results reveal that more $\mathrm{B}^{-s i t e} \mathrm{~Tb}^{4+}$ ions are reduced to $\mathrm{A}$-site $\mathrm{Tb}^{3+}$. The higher sintering temperature is apt to ceramic densification and the incorporation of more $\mathrm{Tb}^{4+}$ ions into B-sites.

\section{KEYWORDS}

Tb-doped BaTiO3 ceramics, X-ray diffraction, mixed-valent state, dielectric properties, electron paramagnetic resonance.

\section{INTRODUCTION}

In the dielectric field, researchers had explored $\mathrm{Tb}$-doped $\mathrm{BaTiO}_{3}\left(\mathrm{ABO}_{3}\right)$ ceramics for thirty years [1-7]. Terbium (Tb) is a valence-variable rareearth element. In compounds, $\mathrm{Tb}$ is considered to exist as $\mathrm{Tb}^{3+}$ or as metastable $\mathrm{Tb}^{4+}$ with a half-filled $4 \mathrm{f}$ shell. Hence, there is controversy over the valence state of $\mathrm{Tb}_{\text {in }} \mathrm{BaTiO}_{3}$. In 2001, Tsur et al anticipated a tendency of B-site occupancy by $\mathrm{Tb}^{4+}$ and indicated that in Ba-rich case $\mathrm{Tb}$ is incorporated into $\mathrm{B}$-site as $\mathrm{Tb}^{4+}$ during sintering and on cooling to room temperature $\mathrm{Tb}^{4+}$ traps a single electron and becomes a large $\mathrm{Tb}^{3+}[1]$. Most research groups thought that $\mathrm{Tb}$ ions are incorporated into $\mathrm{A}$-sites $\mathrm{as}_{\mathrm{Tb}} \mathrm{Tb}^{3+}$ in $\mathrm{BaTiO}_{3}$ before 2012 [2-5]. The abovementioned investigations reveal that the view of point that $\mathrm{Tb}$ exists at A-site or B-site as $\mathrm{Tb}^{3+}$ prevails in Tb-doped $\mathrm{BaTiO}_{3}$. Until 2015, the electron paramagnetic resonance (EPR) monitoring of $\mathrm{Tb}$-doped $\mathrm{BaTiO}_{3}$ provided direct evidence for presence of $\mathrm{B}$-site $\mathrm{Tb}^{4+}[6]$. Under different $\mathrm{Ba}$ /Ti ratios, $\mathrm{Tb}$ ions in $\mathrm{BaTiO}_{3}$ tend to form self-adjustable site occupations between $\mathrm{A}$-site $\mathrm{Tb}^{3+}$ and B-site $\mathrm{Tb}^{4+}[6]$

The subsequent studies indicated that the self-compensation mode of $\mathrm{Tb}_{\mathrm{Ba}}-\mathrm{Tb}_{\mathrm{Ti}}$ in $\left(\mathrm{Ba}_{1-x} \mathrm{~Tb}_{x}\right)\left(\mathrm{Ti}_{1-x} \mathrm{~Tb}_{x}\right) \mathrm{O}_{3}$ ceramics sintered at a sintering temperature of $T_{\mathrm{s}}=1400^{\circ} \mathrm{C}$ cannot be formed and it is inevitable that some $\mathrm{Tb}$ ions enter B-sites as $\mathrm{Tb}^{4+}$ [7]. Defect notation proposed by Kröger and Vink was adopted [8]. It was also found that Tb cannot exist only as B-site $\mathrm{Tb}^{4+}$ for $\left(\mathrm{Ba}_{1-x} \mathrm{La}_{x}\right)\left(\mathrm{Ti}_{1-x} \mathrm{~Tb}_{x}\right) \mathrm{O}_{3}$ or only as A-site $\mathrm{Tb}^{3+}$ for $\left(\mathrm{Ba}_{1-x} \mathrm{~Tb}_{x}\right)\left(\mathrm{Ti}_{1-x} \mathrm{Dy}_{x}\right) \mathrm{O}_{3} \quad[9,10]$. As a whole, the mixed $\mathrm{Tb}^{3+} / \mathrm{Tb}^{4+}$ is characteristic of $\mathrm{Tb}$ ions in singly- or double-doped $\mathrm{BaTiO}_{3}$. However, little is known about structural and dielectric properties of Tbdoped $\mathrm{BaTiO}_{3}$ ceramics prepared under different conditions.

In this work, the effect of the sintering temperature $\left(T_{\mathrm{s}}\right)$ and the sintering time $(t)$ on structural and dielectric properties of $\mathrm{Tb}$-doped $\mathrm{BaTiO}_{3}$ ceramics was reported. The dielectric stability independent of $T_{\mathrm{s}}$ and $t$ is discovered. The optimum preparation condition is proposed.

\section{EXPERIMENTAL}

pressing ceramic processing technique according to the nominal formula $\mathrm{Ba}_{1-x / 2} \mathrm{Ti}_{1-x / 2} \mathrm{~Tb}_{x} \mathrm{O}_{3}(x=0.05)$ [6]. The initial re-agent powders $\mathrm{BaCO}_{3}, \mathrm{TiO}_{2}$ and $\mathrm{Tb}_{4} \mathrm{O}_{7}$ were weighed ancarefully mixed. The mixture was calcinated in air at $1100{ }^{\circ} \mathrm{C}$ for $5 \mathrm{~h}$ for decarbonation. The mixture with a PVA binder was then uniaxially pressed at $200 \mathrm{MPa}$ for $2 \mathrm{~min}$ into pellets with $12-\mathrm{mm}$ diameter. These pellets were sintered in air at $T_{\mathrm{s}}=1400{ }^{\circ} \mathrm{C}$ for $t=6,12$, and $24 \mathrm{~h}$, respectively (denoted by BTTb5TS); and for $t=24 \mathrm{~h}$ at $T_{\mathrm{s}}=1300$, $1350,1400,1450$, and $1480{ }^{\circ} \mathrm{C}$, respectively (BTTb5t). The pellets were densified into crack-free ceramics.

Powder X-ray diffraction (XRD) measurements were performed using a Rint 2200 X-ray diffractometer (Rigaku). All XRD data were collected between $20^{\circ} \leq 2 \theta \leq 120^{\circ}$ in steps of $0.02^{\circ}$ at room temperature. Crystal structures were determined by MS Modeling (Accelry). The polished disks with $0.8-\mathrm{mm}$ thickness were electroded with sputtered $\mathrm{Au}$ atoms and silver paste and then heat-treated at $500{ }^{\circ} \mathrm{C}$ for $30 \mathrm{~min}$ for electrical measurements. The dielectric properties of ceramics were investigated at $1 \mathrm{kHz}$ using a Dielectric/Impedance spectrometer (Concept 41, Novocontrol) with an applied voltage of $1 \mathrm{~V}$. EPR measurements were performed using an A300-10/12 X-band spectrometer (Bruker) operated at $9.84 \mathrm{GHz}$

\section{RESULTS AND DISCUSSION}

\subsection{Crystal Structure and Relative Density}

The powder XRD patterns of BTTb5 ceramics sintered at $T_{\mathrm{s}}=1400{ }^{\circ} \mathrm{C}$ for different sintering time (BTTb5t) are shown in Figure 1. A (002)/(200) peak splitting is characteristic of the tetragonal perovskite structure (Figure 1 insets). The crystal structure of BTTb5t is tetragonal from $t=6$ to $24 \mathrm{~h}$ and independent of the sintering time. The powder XRD patterns of BTTb5 ceramics sintered for $24 \mathrm{~h}$ at different sintering temperatures (BTTb5TS) are shown in Figure 2. Similar to BTTb5t, the crystal structure of BTTb5TS is still tetragonal from $T_{\mathrm{s}}=1300$ to $1480{ }^{\circ} \mathrm{C}$ and independent of the sintering temperature. 


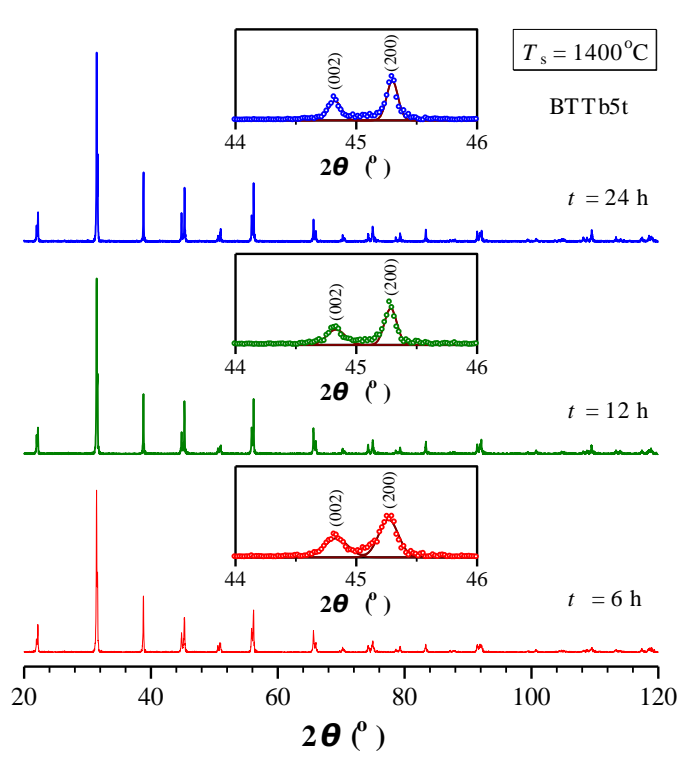

Figure 1: Powder XRD patterns of BTTb5 ceramics sintered at $T_{\mathrm{s}}=1400$ ${ }^{\circ} \mathrm{C}$ (BTTb5t) for 6, 12 and $24 \mathrm{~h}$. Three insets show Gaussian fitting of the XRD peaks in the vicinity of $45^{\circ}$.

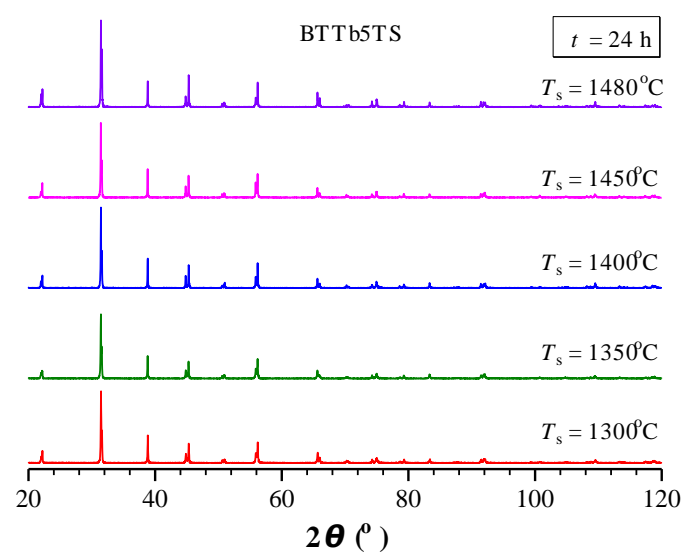

Figure 2: Powder XRD patterns of BTTb5 ceramics sintered at Ts $=1300$, $1350,1400,1450,1480^{\circ} \mathrm{C}$ for $24 \mathrm{~h}$ (BTTb5TS).

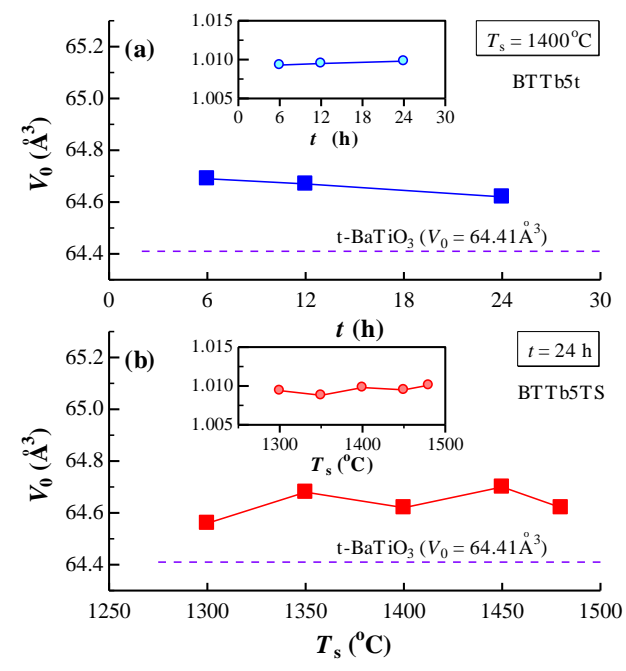

Figure 3: Variations in $V_{0}$ as a function of (a) $t$ for BTTb5t and (b) $T_{\mathrm{s}}$ for BTTb5TS. Two insets show $c / a$ vs $t$ for BTTb5t and $c / a$ vs $T_{\mathrm{s}}$. for BTTb5TS.

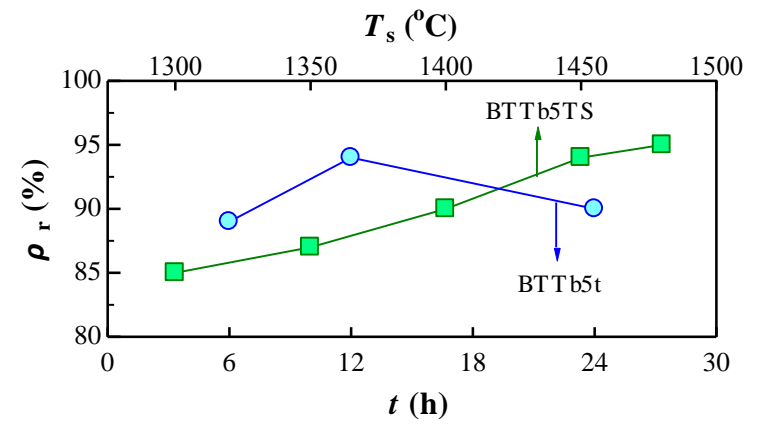

Figure 4: Variations in $\rho_{\mathrm{r}}$ as a function of $t$ for BTTb5t and $T_{\mathrm{s}}$ for BTTb5TS.

The variations in unit-cell volume $\left(V_{0}\right)$ as a function of $t$ for BTTb5t and $T_{\mathrm{s}}$ for BTTb5TS are shown in Figure 3. The $V_{0}$ at $T_{\mathrm{s}}=1400^{\circ} \mathrm{C}$ decreases with increasing $t$ (Figure $3 \mathrm{a}$ ), implying that more $\mathrm{B}$-site $\mathrm{Tb}^{4+}$ ions are reduced to A-site $\mathrm{Tb}^{3+}$. The $V_{0}$ at $t=24 \mathrm{~h}$ changes in M-type when $T_{\mathrm{s}}$ increases from 1300 to $1480{ }^{\circ} \mathrm{C}$ (Figure $3 \mathrm{~b}$ ). The tendency to increase in $V_{0}$ implies that the higher $T_{\mathrm{s}}$ is apt to the incorporation of $\mathrm{Tb}^{4+}$ ions into B-sites. The tetragonality $(c / a)$ is nearly a constant (1.009-1.010), independent of $T_{\mathrm{s}}$ and $t$ (Figure 3 insets). This fact reveals that $\mathrm{Tb}$ ions can be completely incorporated into the $\mathrm{BaTiO}_{3}$ lattice when $T_{\mathrm{s}} \geq 1300^{\circ} \mathrm{C}$ and $t \geq 6 \mathrm{~h}$.

The relative density $\left(\rho_{\mathrm{r}}\right)$ of BTTb5TS increases from 85 to $95 \%$ continuously with increasing $T_{\mathrm{s}}$ from 1300 to $1480{ }^{\circ} \mathrm{C}$. The $\rho_{\mathrm{r}}$ of BTTb5t sintered at $T_{\mathrm{s}}=1400{ }^{\circ} \mathrm{C}$ reaches a maximum value of $94 \%$ at $t=12 \mathrm{~h}$, as shown in Figure 4. Thus, to achieve dense $\mathrm{Tb}$-doped $\mathrm{BaTiO}_{3}$ ceramics, the optimum condition is chosen as $T_{\mathrm{s}}=1400^{\circ} \mathrm{C}$ for $t=12 \mathrm{~h}$.

\subsection{Dielectric Properties}

The temperature dependences of the dielectric permittivity $\left(\varepsilon^{\prime}\right)$ and the dielectric loss $(\tan \delta)$ for BTTb5t are shown in Figure 5. All the BTTb5t ceramics exhibit dielectric-temperature stability below $85^{\circ} \mathrm{C}$, satisfying EIA (Electronic Industries Association) X5R specification. As $t$ increases, the change in dielectric-peak temperature $\left(T_{\mathrm{m}}\right)$ is less than $5^{\circ} \mathrm{C}$, revealing that the concentrations of $\mathrm{A}$-site $\mathrm{Tb}^{3+}$ and $\mathrm{B}$-site $\mathrm{Tb}^{4+}$ alters little, independent of $t$. The room-temperature permittivity $\left(\mathcal{\varepsilon}^{\prime}\right.$ RT) is 1120 . BTTb5t exhibits a lower $\tan \delta(0.0108)$ at roo, temperature when $t \geq 12 \mathrm{~h}$. The shorter sintering time (e.g. $t=6 \mathrm{~h}$ ) will result in an increase in $\tan \delta$.

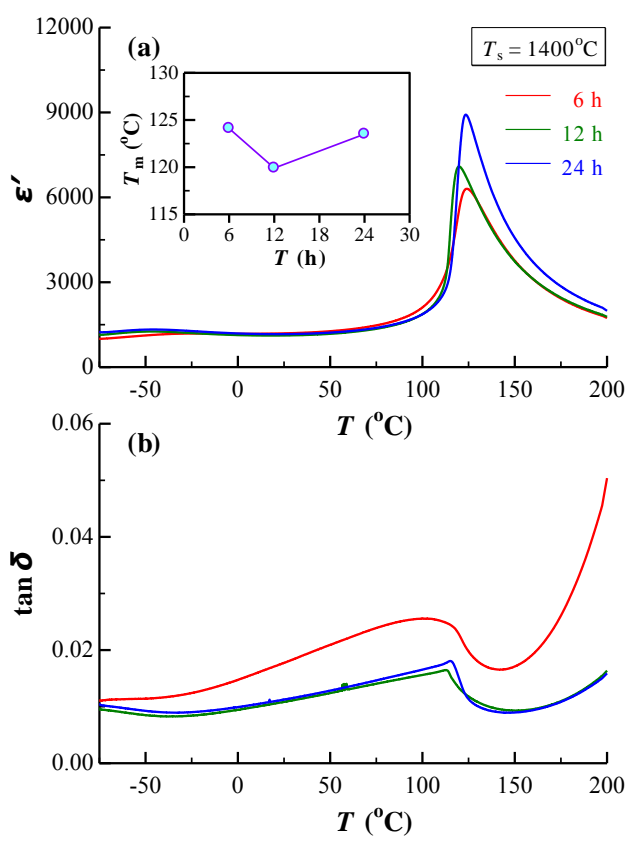

Figure 5: Temperature dependences of (a) $\varepsilon^{\prime}$ and (b) $\tan \delta$ for BTTb5t, measured at $1 \mathrm{kHz}$. The inset depicts $T_{\mathrm{m}}$ vs $t$ for BTTb5t. 

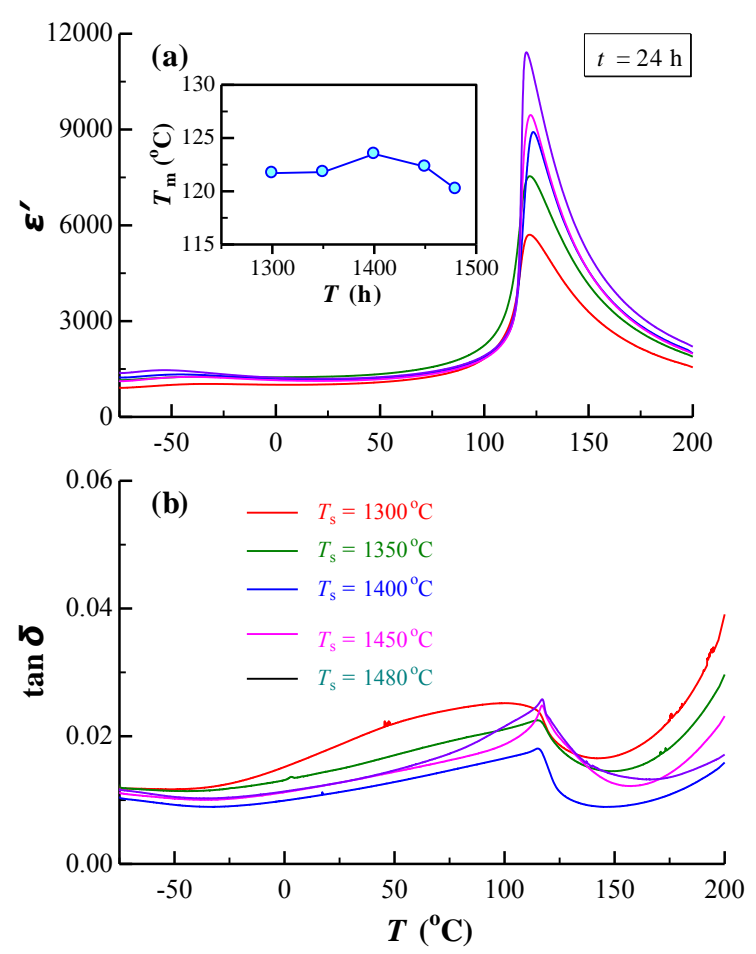

Figure 6: Temperature dependences of (a) $\varepsilon^{\prime}$ and (b) $\tan \delta$ for BTTb5TS, measured at $1 \mathrm{kHz}$. The inset depicts $T_{\mathrm{m}}$ vs $t$ for BTTb5T

The temperature dependences of $\varepsilon^{\prime}$ and $\tan \delta$ for BTTb5TS are shown in Figure 6. BTTb5TS keeps a stable permittivity in the X5R temperature region. A lower sintering temperature of $T_{\mathrm{s}}=1300^{\circ} \mathrm{C}$ is not advantageous to the fabrication of Tb-doped $\mathrm{BaTiO}_{3}$ ceramic owing its lower $\varepsilon^{\prime}$ and higher $\tan \delta$. Raising $T_{\mathrm{s}}$ has little influence on $\varepsilon^{\prime}{ }_{\mathrm{RT}}$, but the maximum permittivity $\left(\varepsilon^{\prime} \mathrm{m}\right)$ is greatly improved. At $T_{\mathrm{s}}=1400^{\circ} \mathrm{C}$, when $t$ is increased from 12 to $24 \mathrm{~h}, \varepsilon_{\mathrm{RT}}^{\prime}$ is increased slightly from 1120 to 1170 , suggesting that the selection of $t=12 \mathrm{~h}$ is very reasonable. It can be seen from Figure 6 that BTTb5TS sintered at $T_{\mathrm{s}}=1400^{\circ} \mathrm{C}$ relative to other ceramics exhibits the lowest $\tan \delta$. These investigations further clarify that the optimum condition is $T_{\mathrm{s}}=1400^{\circ} \mathrm{C}$ for $t=12 \mathrm{~h}$ for Tb-doped $\mathrm{BaTiO}_{3}$ ceramics. Thus, we prepared $\left(\mathrm{Ba}_{1-x} \mathrm{La}_{x}\right)\left(\mathrm{Ti}_{1-x} \mathrm{~Tb}_{x}\right) \mathrm{O}_{3}$ [9] and $\left(\mathrm{Ba}_{1-x} \mathrm{~Tb}_{x}\right)\left(\mathrm{Ti}_{1-x} \mathrm{Dy}_{x}\right) \mathrm{O}_{3}$ [10] ceramics according to this condition $[9,10]$.

\subsection{Electron Paramagnetic Resonance and Point Defects}

The EPR spectra of BTTb5t are shown in Figure 7. A broad signal at $g=$ 5.68-5.81 is assigned to $\mathrm{Tb}^{4+}$ and its $g$ value decreases slightly with increasing $t[6,7,9,10]$. It is known that the $g$ value increases with increasing the $\mathrm{Ba} / \mathrm{Ti}$ ratio. That is to say, an increase in $g$ is in accordance with an increase in the concentration of B-site $\mathrm{Tb}^{4+}$ ions [6]. This fact suggests that the increase in sintering time results in a decrease in the concentration of B-site $\mathrm{Tb}^{4+}$ ions, which agree with the $\mathrm{XRD}$ result.

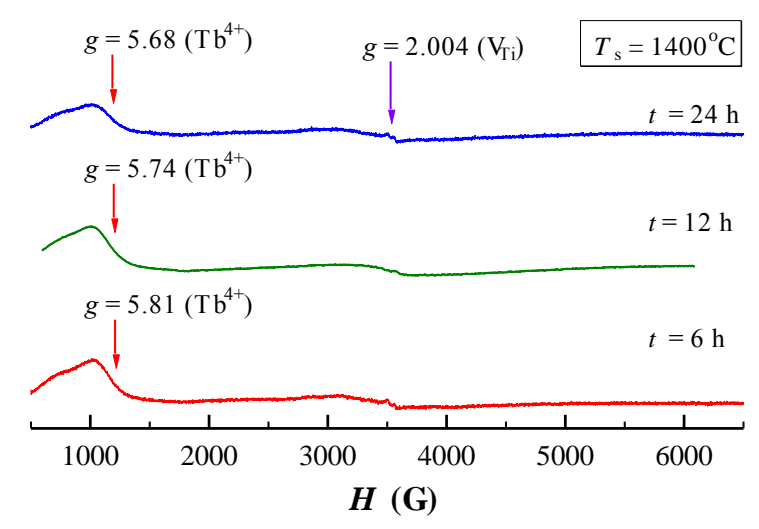

Figure 7: EPR spectra of BTTb5t.

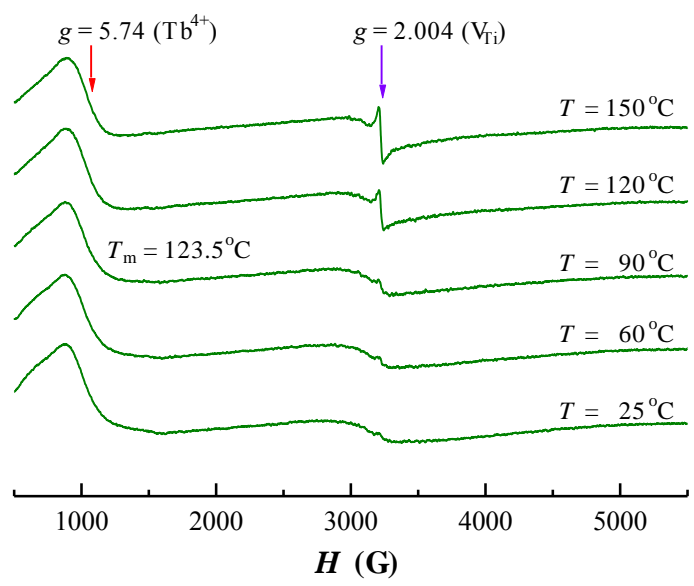

Figure 8: Temperature-dependent EPR spectra of BTTb5 sintered at Ts = $1400^{\circ} \mathrm{C}$ for $12 \mathrm{~h}$ (i.e. BTTb5t with $\mathrm{t}=12 \mathrm{~h}$ ).

A weak signal appears in the vicinity of $3500 \mathrm{G}$. To investigate the origin of this weak signal, the temperature-dependent EPR spectra of BTTb5 sintered at $T_{\mathrm{s}}=1400^{\circ} \mathrm{C}$ for $12 \mathrm{~h}$ (i.e. BTTb5t with $t=12 \mathrm{~h}$ ) were measured, as shown in Figure 8 . This weak signal is markedly activated above $120^{\circ} \mathrm{C}$, near the tetragonal-cubic phase transition point $\left(T_{\mathrm{m}}=123.5^{\circ} \mathrm{C}\right)$. For this reason, this weak signal is attributed to ionized Ti vacancies [6]. The existence of Ti vacancies in BTTb5t is apt to the Ti-site occupations by the larger $\mathrm{Tb}^{4+}$ ions $(0.76 \AA)$ [11].

The formula $\left(\mathrm{Ba}_{1-x / 2} \mathrm{~Tb}_{x / 2}\right)\left(\mathrm{Ti}_{1-x / 2} \mathrm{~Tb}_{x / 2}\right) \mathrm{O}_{3}$ with a self-compensation mode cannot be formed due to the existence of $\mathrm{B}$-site $\mathrm{Tb}^{4+}$ and Ti vacancies. The concentration of A-site $\mathrm{Tb}^{3+}$ ions must be higher than that of $\mathrm{B}$-site $\mathrm{Tb}^{4+}$ ions to keep lattice electroneutrality.

\section{CONCLUSION}

$\mathrm{Ba}_{1-x / 2} \mathrm{Ti}_{1-x / 2} \mathrm{~Tb}_{x} \mathrm{O}_{3}(x=0.05)$ ceramics (BTTb5) were prepared at $T_{\mathrm{s}}=$ $1400{ }^{\circ} \mathrm{C}$ for $t=6-24 \mathrm{~h}$ (BTTb5t) and at $T_{\mathrm{s}}=1300-1480{ }^{\circ} \mathrm{C}$ for $t=24 \mathrm{~h}$ (BTTb5TS) using the cold-pressing ceramic processing technique. All the BTTb5 ceramics satisfy EIA X5R specification and exhibit a tetragonal perovskite structure. The sintering temperature and the sintering time have little influence on the crystal structure and dielectric properties of BTTb5. The optimum preparation condition of BTTb5 is determined as $T_{\mathrm{s}}$ $=1400{ }^{\circ} \mathrm{C}$ for $t=12 \mathrm{~h}$ because of higher relative density $\left(\rho_{\mathrm{r}}=94 \%\right)$ and lower dielectric loss $(\tan \delta=0.0108)$. When $T_{\mathrm{s}}=1400^{\circ} \mathrm{C}$, as the sintering time increases, both $V_{0}$ and the $g$ value of the EPR signal of $\mathrm{Tb}^{4+}$ decrease (from 5.81 to 5.68). These two XRD and EPR results reveal that more Bsite $\mathrm{Tb}^{4+}$ ions are reduced to $\mathrm{A}$-site $\mathrm{Tb}^{3+}$. The higher $T_{\mathrm{s}}$ is apt to ceramic densification and incorporation of more $\mathrm{Tb}^{4+}$ ions into B-sites.

\section{ACKNOWLEDGMENTS}

This work was supported by the projects of the National Natural Science Foundations of China (21271084) and of Jilin Province (20160101290JC), and Changbai Mountain Scholar Distinguished Professor (2015047).

\section{REFERENCE}

[1] Tsur, Y., Dunbar, T.D., Randall, C.A. 2001. Crystal and defect chemistry of rare earth cations in $\mathrm{BaTiO}_{3}$. Journal of Electroceramics, 7, 25-34.

[2] Xue, L.A., Chen, Y., Brook, R.J. 1988. The influence of ionic radii on the incorporation of trivalent dopants into $\mathrm{BaTiO}_{3}$. Materials Science and Engineering B, 1 (2), 193-201.

[3] Buscaglia, M.T., Buscaglia, V., Viviani, M., Nanni, P., Hanuskova, M. 2000. Influence of foreign ions on the crystal structure of $\mathrm{BaTiO}_{3}$. Journal of European Ceramic Society, 20 (12), 1997-2007.

[4] Buscaglia, M.T., Buscaglia, V., Viviani, M., Nanni, P. 2004. Atomistic simulation of dopant incorporation in barium titanate. Journal of American Ceramic Society, 84 (2), 376-384.

[5] Li, Y.X., Yao, X., Wang, X.S., Hao, Y.B. 2012. Study of dielectric properties of rare earth $(\mathrm{Dy}, \mathrm{Tb}, \mathrm{Eu})$ doped barium titanate sintered in pure nitrogen. Ceramics International, 38 (1), S29-S32. 
[6] Lu, D.Y. 2015. Self-adjustable site occupations between Ba-site $\mathrm{Tb}^{3+}$ and $\mathrm{Ti}$-site $\mathrm{Tb}^{4+}$ ions in terbium-doped barium titanate ceramics. Solid State Ionics, 276, 98-106.

[7] Lu, D.Y., Peng, Y.Y. 2016. Dielectric properties and exploration of selfcompensation mode of $\mathrm{Tb}$ in $\mathrm{BaTiO}_{3}$ ceramics. Journal of the Ceramic of Japan, 124 (4), 455-459.

[8] Kröger, F.A., Vink, H.J. in: Seitz, F., Turnbull, D. (Eds.). 1956. Relations between the Concentrations of Imperfections in Crystalline Solids, in Solid State Physics. Academic Press, New York.
[9] Lu, D.Y., Peng, Y.Y., Yu, X.Y., Sun, X.Y. 2016. Dielectric properties and defect chemistry of $\mathrm{La}$ and $\mathrm{Tb}$ co-doped $\mathrm{BaTiO}_{3}$ ceramics. Journal of Alloy and Compounds, 681, 128-138.

[10] Lu, D.Y., Cui, S.Z., Liu, Q.L., Sun, X.Y. 2016. Dielectric properties and defect chemistry of barium titanate ceramics co-doped $\mathrm{R}$ and Dy ions $(\mathrm{R}=\mathrm{Eu}, \mathrm{Gd}, \mathrm{Tb})$. Ceramics International, 42 (13), 14364-14373.

Shannon, R.D. 1976. Revised effective ionic radii and systematic studies of interatomic distances in halides and chalcogenides. Acta Crystallography Section A, 32, 751-767. 